Jurnal Sulolipu : Media Komunikasi Sivitas Akademika dan Masyarakat

Vol. 20 No.12020

e-issn : 2622-6960, p-issn : 0854-624X

\title{
FAKTOR YANG BERHUBUNGAN DENGAN RISIKO KECELAKAAN KERJA DI PT. MARUKI INTERNASIONAL INDONESIA BAGIAN PRODUKSI
}

\author{
Sri Sudiar ${ }^{1}$ dan Hamsir² \\ 12 Jurusan Kesehatan Lingkungan Poltekkes Kemenkes Makassar \\ *sriisudiar@gmail.com
}

\begin{abstract}
Occupational safety and health or OSH are inseparable in the labor system and human resources. Health and safety are not only very important in increasing social security and the welfare of its workers, but far from that occupational safety and health has a positive impact on the sustainability of its work productivity. The purpose of this study is to determine the factors associated with the risk of workplace accidents at PT. Maruki International Indonesia production section. The research method used is analytical observational, namely with the Crossectional approach. The independent and dependent variables are examined together. The sample in this study were employees, 154 were obtained from calculations using the formula (Slovin). The results showed that of 154 respondents, 106 (68.83\%) respondents knew and 48 (31.16\%) respondents did not know. For the use of PPE 135 (87.66\%) of respondents who met the requirements for PPE use, 19 (12.87\%) respondents who did not meet the requirements for using PPE, for ergonomics 112 (73.37\%) respondents who met the requirements for implementing Ergonomics, 41 ( 26.62\%) respondents did not meet the requirements for implementing Ergonomics. Based on the results of the study it can be concluded that there is no relationship between Knowledge, Use of PPE, and Ergonomics with Occupational Accident Risk. It is hoped that there will be more stringent supervision from the company so that the risk of accidents can be reduced to a minimum.
\end{abstract}

Keywords: Knowledge, PPE, Ergonomics, and Risk of accidents.

\section{ABSTRAK}

Keselamatan dan kesehatan kerja atau K3 merupakan hal yang tidak terpisahkan dalam sistem ketenagakerjaan dan sumber daya manusia.Kesehatan dan keselamatan kerja tidak saja sangat penting dalam meningkatkan jaminan sosial dan kesejahteraan para pekerjanya akan tetapi jauh dari itu keselamatan dan kesehatan kerja berdampak positif atas keberlanjutan produktivitas kerjanya. Tujuan penelitian ini untuk mengetahui faktor yang berhubungan dengan risiko kecelakaan kerja di PT. Maruki Internasional Indonesia bagian produksi. Metode penelitian yang digunakan bersifat observasional analitik yaitu dengan pendekatan crossectional.dengan variabel independen dan dependen diteliti secara bersama. Sampel dalam penelitian ini adalah 154 responden dengan teknik pengambilan random sapling. Hasil penelitian diperoleh hasil bahwa dari 154 responden, $106(68,83 \%)$ responden yang mengetahui dan $48(31,16 \%)$ responden yang tidak mengetahui dengan hasil $p=0,996$. Untuk penggunaan Alat Pelindung Diri (APD) 135 (87,66\%) responden yang memenuhi syarat penggunaan APD, 19 (12,87\%) responden yang tidak memenuhi syarat penggunaan APD dengan hasil $p=0,812$ untuk ergonomi 112 (73,37\%) responden yang memenuhi syarat penerapan Ergonomi, 41 (26,62\%) responden tidak memenuhi syarat penerapan Ergonomi dengan hasil $p=0,006$. Berdasarkan hasil penelitian dapat disimpulkan bahwa tidak terdapat hubungan antara Pengetahuan, Penggunaan APD dengan Risiko Kecelakaan Kerja dan ada hubungan antara ergonomi dengan risiko kecelakaan kerja. Diharapkan adanya pengawasan lebih ketat dari pihak perusahaan agar risiko kecelakaan dapat ditekan seminimal mungkin.

Kata kunci : Pengetahuan, APD, Ergonomi dan Risiko kecelakaan.

\section{PENDAHULUAN}

Keselamatan dan kesehatan kerja atau K3 merupakan hal yang tidak terpisahkan dalam sistem ketenagakerjaan dan sumber daya manusia.Kesehatan dan keselamatan kerja tidak saja sangat penting dalam meningkatkan jaminan sosial dan kesejahteraan para pekerjanya akan tetapi jauh dari itu keselamatan dan kesehatan kerja berdampak positif atas keberlanjutan produktivitas kerjanya. (Irzal 2016).

Kecelakaan kerja sering terjadi di perusahaan / industri yang disebabkan karena kurangnya penerapan K3 dan pengawasan terhadap karyawan mengenai penggunaan APD. Hal ini dalam jumlah kasus kecelakaan kerja di Indonesia pada tahun 2005,2006 dan 2007 yaitu 99,023 kasus, 95,624 kasus dan 37,845 kasus. Ribka (2014) dalam Ayu (2015).

Menurut perkiraan terbaru yang dikeluarkan oleh Organisasi Perburuhan Internasional (ILO), 2,78 juta pekerja meninggal setiap tahun karena kecelakaan kerja dan penyakit akibat kerja.1 Sekitar 2,4 juta (86,3 persen) dari kematian ini dikarenakan penyakit akibat kerja, sementara lebih dari 380.000 (13,7 persen) dikarenakan kecelakaan kerja. Setiap tahun, ada hampir seribu kali lebih banyak kecelakaan kerja non-fatal dibandingkan kecelakaan kerja fatal. Kecelakaan nonfatal diperkirakan dialami 374 juta pekerja setiap tahun, dan banyak dari kecelakaan ini memiliki konsekuensi yang serius terhadap kapasitas penghasilan para pekerja (Hamalainen et al., 2017).

Badan Penyelenggara Jaminan Sosial (BPJS) Ketenagakerjaan mencatat angka kecelakaan kerja di Indonesia cenderung terus meningkat. Tahun 2015 terjadi kecelakaan kerja sebanyak 110.285 kasus, sedangkan tahun 2016 sejumlah 105.182 kasus, Sebanyak 123 ribu kasus kecelakaan kerja tercatat sepanjang 2017, menurut statistik terjadi peningkatan kecelakaan kerja sekitar 20 persen dibandingkan 2016 secara nasional, Total kecelakaan kerja pada 2017 sebanyak 123 ribu kasus dengan nilai klaim Rp 971 miliar lebih. Angka ini meningkat dari tahun 2016 dengan nilai klaim hanya Rp 792 miliar lebih. Khusus Jakarta saja terjadi 
peningkatan angka kecelakaan kerja hingga 10 persen pada 2017 (BPJS 2018). Faktor risiko terjadinya kecelakaan kerja dapat pula terjadi di PT. Maruki Internasional Indonesia, dimana industri ini bergerak di bidang industri kayu yang memiliki beberapa faktor risiko terjadinya kecelakaan kerja dan penyakit akibat kerja adalah penerapan $\mathrm{K} 3$ yang kurang baik, penggunaan APD, suhu kondisi lingkungan kerja, ergonomi saat kerja dan lain-lain yang mempengaruhi keselamatan dan kesehatan kerja karyawan, sehingga menimbulkan beberapa dampak penyakit terhadap karyawan yang dapat mempengaruhi kesehatannya.

Berdasarkan data 5 tahun terakhir yang di dapatkan di PT. Maruki Internasional Indonesia dari 515 orang karyawan. Terdiri dari 398 orang laki-laki dan 120 orang perempuan. terjadi kecelakaan akibat kerja pada tahun 2014 sebanyak 22 orang, tahun 2015 sebanyak 20 orang, tahun 2016 sebanyak 8 orang, tahun 201711 orang,dan 2018 sebanyak 4 orang.Kebanyakan kecelakaan terjadi pada saat bekerja di bagian mesin.Dalam penelitian ini apa faktor-faktor kesehatan dan keselamatan kerja yang berhubungan dengan risiko kecelakaan kerja di PT. Maruki Internasional Indonesia bagian produksi.

\section{METODE PENELITIAN}

Tempat dan waktu

Terletak di PT. Maruki Internasional Indonesia dengan 2 tahapan yaitu Tahap persiapan yang meliputi observasi dan pengumpulan data sekunder yang berlangsung pada bulan Desember 2018 - januari 2019 dan Tahap pelaksana meliputi kegiatan penelitian yang berlangsung pada bulan April-Mei 2019.

\section{Variabel penelitian}

Variabel bebas terdiri dari pengetahuan, APD, ergonomi sedangkan variabel terikat yaitu Risiko kecelakaan dan variabel pengganggu yaitu pendidikan, masa kerja dan umur.

\section{Populasi}

Yang menjadi populasi dari penelitian ini adalah seluruh karyawan yang ada di PT. Maruki Internasional Indonesia di bagian produksi yang berjumlah 250 karyawan.

\section{Sampel}

Sampel dalam penelitian ini adalah karyawan yang bekerja di PT. Maruki Internasional Indonesia di bagian produksi, Sebanyak 154 yang didapatkan dari perhitungan dengan menggunakan rumus (Slovin).

\section{Pengumpulan data}

Data primer yang dimaksud adalah data penelitian yang diperoleh dari hasil observasi di PT.maruki internasional Indonesia.

Data sekunder yang dimaksud adalah data yang diperoleh dari klinik kesehatan PT. Maruki Internasional Indonesia.

\section{Pengolahan data}

Pengolahan data dilakukan dengan menggunakan computer melalui tahap Editing,coding, entry data dan tabulasi.

\section{Analisa data}

Analisa ini dilakukan terhadap setiap variabel dari hasil penelitian ini untuk melihat distribusi frekuensi dan presentase yaitu meliput pengetahuan, penggunaan APD, dan Ergonomi

\section{HASIL}

Tabel 1

Distribusi Responden Berdasarkan Umur di PT.Maruki Internasional Indonesia

\begin{tabular}{|c|c|c|c|}
\hline $\mathrm{NO}$ & Umur & Jumlah & $\%$ \\
\hline 1 & $24-32$ & 34 & 22.1 \\
\hline 2 & $33-41$ & 82 & 53.2 \\
\hline 3 & $42-50$ & 32 & 20.8 \\
\hline 4 & $52-60$ & 6 & 3.9 \\
\hline \multicolumn{2}{|c|}{ Total } & 154 & 100 \\
\hline
\end{tabular}

Tabel 2

Distribusi Responden Berdasarkan Masa Kerja Di PT. Maruki Internasional Indonesia

\begin{tabular}{cccc}
\hline NO & $\begin{array}{c}\text { Masa } \\
\text { Kerja }\end{array}$ & Jumlah & $\%$ \\
\hline $\mathbf{1}$ & $\begin{array}{c}4-10 \\
\text { tahun }\end{array}$ & 88 & 57.1 \\
$\mathbf{2}$ & $\begin{array}{l}11-20 \\
\text { tahun } \\
\mathbf{3}\end{array}$ & $621-30$ & 40.3 \\
tahun & 4 & 2.6 \\
\hline & Total & 154 & 100 \\
\hline
\end{tabular}

Sumber : Data Primer

Tabel 3

Distribusi Responden Berdasarkan Pendidikan Di PT.

\begin{tabular}{cccc}
\multicolumn{4}{c}{ Maruki Internasional Indonesia } \\
\hline NO & Pendidikan & Jumlah & $\%$ \\
\hline $\mathbf{1}$ & SD & 88 & 35.7 \\
$\mathbf{3}$ & SMP & 28 & 18.2 \\
& SMA/SMK & 67 & 43.5 \\
$\mathbf{4}$ & Perguruan & 4 & 2.6 \\
& Tinggi & & \\
\hline & Total & 154 & 100 \\
\hline
\end{tabular}

Sumber : Data Primer 
Jurnal Sulolipu : Media Komunikasi Sivitas Akademika dan Masyarakat

Vol. 20 No. 12020

e-issn : 2622-6960, p-issn : 0854-624X

Tabel 4

Berdasarkan Pengetahuan Di PT. Maruki Internasional Indonesia

\begin{tabular}{|c|c|c|c|}
\hline $\mathrm{NO}$ & $\begin{array}{c}\text { Kriteria } \\
\text { Pengetahuan }\end{array}$ & Jumlah & $\%$ \\
\hline 1 & Tahu & 106 & 68,83 \\
\hline 2 & Tidak Tahu & 48 & 31,16 \\
\hline & Total & 154 & 100 \\
\hline \multicolumn{4}{|c|}{ Sumber: Data Primer } \\
\hline \multicolumn{4}{|c|}{$\begin{array}{c}\text { Tabel } 5 \\
\text { Berdasarkan Penggunaan APD Di PT. Maruk } \\
\text { Internasional Indonesia }\end{array}$} \\
\hline NO & $\begin{array}{c}\text { Kriteria } \\
\text { APD }\end{array}$ & Jumlah & $\%$ \\
\hline 1 & Memenuhi & 135 & 87,66 \\
\hline 2 & $\begin{array}{c}\text { Tidak } \\
\text { Memenuhi }\end{array}$ & 19 & 12,87 \\
\hline & Total & 154 & 100 \\
\hline
\end{tabular}

Tabel 6

Berdasarkan Penerapan Ergonomi Di PT. Maruki Internasional Indonesia

\begin{tabular}{cccc}
\hline NO & $\begin{array}{c}\text { Kriteria } \\
\text { Ergonomi }\end{array}$ & Jumlah & $\%$ \\
\hline $\mathbf{1}$ & Memenuhi & 113 & 73,37 \\
& $\begin{array}{c}\text { Tidak } \\
\text { Memenuhi }\end{array}$ & 41 & 26,62 \\
\hline & Total & 154 & 100 \\
\hline
\end{tabular}

Tabel 7

Hubungan Pengetahuan dengan Risiko Kecelakaan di PT. Maruki Internasional Indonesia

\begin{tabular}{|c|c|c|c|c|c|c|c|}
\hline \multirow{3}{*}{$\begin{array}{l}\text { Pengetah } \\
\text { uan }\end{array}$} & \multicolumn{4}{|c|}{ Risiko Kecelakaan } & \multirow{3}{*}{$\begin{array}{c}\text { Tot } \\
\text { al }\end{array}$} & \multirow{3}{*}{$\alpha$} & \multirow{3}{*}{$P$} \\
\hline & $\begin{array}{c}\text { Berisi } \\
\text { ko }\end{array}$ & & $\begin{array}{l}\text { Tidak } \\
\text { Berisi } \\
\text { ko }\end{array}$ & & & & \\
\hline & $\mathrm{N}$ & $\%$ & $\mathrm{~N}$ & $\%$ & & & \\
\hline Tidak & 29 & $\begin{array}{l}18 \\
8\end{array}$ & 19 & $\begin{array}{l}12, \\
3\end{array}$ & 100 & \multirow{3}{*}{$\begin{array}{c}0,0 \\
5\end{array}$} & \multirow{3}{*}{$\begin{array}{l}0,9 \\
96\end{array}$} \\
\hline Ya & 64 & $\begin{array}{c}41 \\
5\end{array}$ & 42 & $\begin{array}{c}27, \\
2\end{array}$ & 100 & & \\
\hline Jumlah & 93 & $\begin{array}{c}60 \\
3\end{array}$ & 61 & $\begin{array}{c}39 \\
5\end{array}$ & 100 & & \\
\hline
\end{tabular}

Sumber : Data Primer

Tabel 8

Hubungan Penggunaan APD dengan Risiko Kecelakaan di PT. Maruki Internasional Indonesia

\begin{tabular}{|c|c|c|c|c|c|c|c|}
\hline \multicolumn{6}{|c|}{ Risiko Kecelakaan } & \multirow{3}{*}{$\alpha$} & \multirow{3}{*}{$P$} \\
\hline \multirow{2}{*}{ APD } & \multicolumn{2}{|l|}{$\begin{array}{c}\text { Berisik } \\
0\end{array}$} & \multicolumn{2}{|l|}{$\begin{array}{l}\text { Tidak } \\
\text { Berisik } \\
0\end{array}$} & \multirow{2}{*}{ Total } & & \\
\hline & $\mathrm{N}$ & $\%$ & $\mathrm{~N}$ & $\%$ & & & \\
\hline Tidak & 11 & $\begin{array}{l}57 \\
8 \\
\end{array}$ & 8 & 42,1 & 100 & $\begin{array}{l}0,0 \\
5\end{array}$ & $\begin{array}{c}0,81 \\
2\end{array}$ \\
\hline $\mathrm{Ya}$ & 82 & $\begin{array}{c}60 \\
7 \\
\end{array}$ & 53 & 39,2 & 100 & & \\
\hline $\begin{array}{c}\text { Jumla } \\
h\end{array}$ & 93 & 118 & 61 & 81,3 & 100 & & \\
\hline
\end{tabular}

Tabel 9

Hubungan Penerapan Ergonomi dengan Risiko Kecelakaan di PT. Maruki Internasional Indonesia

\begin{tabular}{|c|c|c|c|c|c|c|c|}
\hline \multirow{3}{*}{$\begin{array}{l}\text { Ergono } \\
\text { mi }\end{array}$} & \multicolumn{4}{|c|}{ Risiko Kecelakaan } & \multirow{3}{*}{$\begin{array}{c}\text { Tot } \\
\text { al }\end{array}$} & \multirow{3}{*}{$\alpha$} & \multirow{3}{*}{$P$} \\
\hline & \multirow{2}{*}{$\begin{array}{c}\begin{array}{c}\text { Berisi } \\
\text { ko }\end{array} \\
\mathrm{N}\end{array}$} & \multicolumn{3}{|c|}{$\begin{array}{c}\text { Tidak } \\
\text { Berisi } \\
\text { ko }\end{array}$} & & & \\
\hline & & $\%$ & $\mathrm{~N}$ & $\%$ & & & \\
\hline Tidak & 25 & $\begin{array}{c}60 \\
9\end{array}$ & 16 & 39 & 100 & & \\
\hline Ya & 41 & $\begin{array}{c}36 \\
9\end{array}$ & 72 & $\begin{array}{c}63 \\
7\end{array}$ & 100 & $\begin{array}{c}0,0 \\
5\end{array}$ & $\begin{array}{c}0,00 \\
6\end{array}$ \\
\hline Jumlah & 66 & $\begin{array}{c}97 \\
8\end{array}$ & 88 & $\begin{array}{c}10 \\
2 \\
\end{array}$ & 100 & & \\
\hline
\end{tabular}

Sumber : Data Primer

\section{PEMBAHASAN}

\section{Hubungan Pengetahuan dengan Risiko Kecelakaan}

Pengetahuan karyawan dalam penelitian ini adalah mencakup tentang pengertian Risiko kecelakaan yang terjadi pada karyawan di bagian produksi, Beberapa aspek penilaian terhadap pengetahuan karyawan dapat menjadi indikasi akan pemahaman yang lebih mendalam dari karyawan tentang Risiko kecelakaan.

Selain itu, aspek penilaian juga dapat membantu dalam mengindikasi status pengetahuan dimana karyawan yang memiliki jawaban dengan skor yang rendah memberikan indikasi kurangnya pengetahuan karyawan tentang Risiko Kecelakaan, Sedangkan skor tertinggi memberikan indikasi cukupnya pengetahuan karyawan tentang Risiko Kecelakaan.

Berdasarkan Hasil uji chi square ( tabel 3 ) di peroleh $p$ value $0,996(0,05)$ pengetahuan karyawan di PT. Maruki Internasional Indonesia Bagian Produksi tidak ada hubungan terhadap Risiko kecelakaan karena sebagian besar karyawan mengetahui Risiko kecelakaan yang terjadi pada saat bekerja. 
Hal ini sejalan dengan penelitian yang dilakukan oleh Sylvia Puspitasari (2018) dengan judul Faktor-faktor yang berhubungan dengan kecelakaan kerja tertusuk jarum suntik atau benda tajam lainnya pada perawat di RSUD Leuwillang Kabupaten Bogor dengan menggunakan Uji Chi Square $\left(\mathrm{X}^{2}\right)$ didapatkan pvalue sebesar 0,190 berarti pvalue $<(0,05)$ pengetahuan perawat tidak ada hubungan dengan kecelakaan kerja tertusuk jarum suntik atau benda tajam.

Oleh karena itu maka penulis mengambil kesimpulan bahwa adapun variabel pengganggu seperti umur dan pendidikan menjadi salah satu faktor penyebab kecelakaan kerja.

$\mathrm{Hal}$ ini menjelaskan responden yang berumur 24-41 memiliki pengetahuan yang baik dan responden yang berumur 42-50 memiliki pengetahuan yg kurang. Hal in terjadi karena responden yang berumur 21-41 memiliki rasa pengetahuan yang lebih tinggi sedangkan responden yang berumur 42-50 kadang kurang memperhatikan sehingga memiliki pengetahuan yang kurang.

Hasil (tabel 2) menunjukkan bahwa dari 154 jumlah responden, $55(35,7 \%)$ responden yang berpendidikan SD, $28(18,2 \%)$ responden yang berpendidikan SMP, $67(43,5 \%)$ responden yang berpendidikan SMA/SMK, dan $4(2,6 \%)$ responden berpendidikan PT/Perguruan Tinggi.

Hal ini sejalan dengan penelitian yang dilakukan oleh Anugrah S (2018) dengan judul Hubungan Perilaku Pekerja dengan Penggunaan Alat Pelindung Diri (APD) di Pabrik Penggilingan Padi di Kabupaten Sidrap bahwa hasil uji statistik dengan menggunakan uji Chi Square $\left(\mathrm{X}^{2}\right)$ didapatkan pvalue sebesar 0,124 yang berarti pvalue $>(0,05)$ pengetahuan pekerja tidak mempunyai hubungan terhadap pengunaan APD hal ini disebabkan karena sebagian besar pekerja atau mengtahui tentang alat pelindung diri itu sendiri tapi kebanyakan mereka tidak mengunakannya karena alasan kurang nyaman, menyusahkan, dan terasa kaku pada saat bekerja.

\section{Hubungan Penggunaan APD dengan Risiko Kecelakaan}

APD Adalah peralatan keselamatan yang harus digunakan oleh personel apabila berada pada suatu tempat kerja yang berbahaya. Kewajiban menggunakan APD itu sendiri telah disepakati oleh perusahaan untuk karyawan.

Dari hasil uji chi square ( tabel 4) di peroleh $p$ value $0,812(0,05)$ menunjukkan bahwa dari 154 responden, 135 (87,66\%) responden yang memenuhi syarat Penggunaan APD, dan 19 (12,87\%) responden tidak memenuhi syarat Penggunaan APD.Penelitian ini menunjukkan tidak ada hubungan antara penggunaan APD dengan Risiko kecelakaan karena di industri tersebut sudah disiapkan APD oleh perusahaan dan adanya peraturan yang mewajibkan karyawan penggunakan APD pada saat bekerja.

Tetapi hasil dilapangan yang dilihat secara langsung berbeda dengan dengan hasil uji Chi Square karena beberapa karyawan yg tidak menggunakan APD. Padahal APD sudah tersedia tetapi karyawan mengatakan kurang merasa nyaman dalam menggunakan APD karena dapat mempengaruhi konsentrasi pada saat bekerja.

Oleh karena itu maka penulis mengambil kesimpulan bahwa kelalaian pada saat bekerja menjadi salah satu faktor penyebab kecelakaan kerja. beberapa karyawan secara tidak sengaja tidak menggunakan APD yang disiapkan oleh industri, contonya adalah masker dan sarung tangan padahal pada bagian pemotongan yang memiliki risiko besar terjadinya kecelakaan. Faktor lain juga seperti tindakan dalam penggunaan APD, masih terdapat beberapa karyawan yg tidak menggunakan APD dikarenakan kurangnya pengawasan untuk menggunakan APD sehingga dapat memungkinkan terjadinya risiko kecelakaan yang merugikan diri sendiri maupun perusahaan.

Hal ini sejalan dengan hasil penelitian yang dilakukan oleh Rachmawaty (2014) dengan judul Hubungan antara Pengetahuan, Sikap dan Tindakan Karyawan dengan penggunaan APD pada Unit Produksi PT. Semen Tonasa. Menunjukkan bahwa dari hasil uji Chi Square diperoleh $x^{2}$ hitung $=147,711$, dimana $d f=100$, $\alpha=0,05$ dengan tingkat keyakinan $95 \%$. Hal ini menunjukkan $x^{2}$ hitung $>x^{2}$ tabel dapat disimpulkan Ho ditolak Ha diterima yang berarti ada hubungan antara tindakan dengan penggunaan APD tetapi masih tergantung pada tuntutan dan pengawasan. Sehingga pengawasan maupun kesadaran dari para pekerja itu sendiri perlu ditingkatkan untuk meminimalisir atau mengurangi tingkat kecelakaan akibat kerja terhadap karyawan yang kurang memperhatikan penggunaan alat pelindung diri.

Jika melihat dari data sekunder terjadi kecelakaan kerja pada tahun 2014 sebanyak 22 orang, tahun 2015 sebanyak 20 orang, tahun 2016 sebanyak 8 orang, tahun 2017 sebanyak sebanyak 11 orang, dan tahun 2018 sebanyak 4 orang mengalami kecelakaan kerja. Setiap tahunnya angka kecelakaan di PT. Maruki Internasional Indonesia mengalami penurunan. Hal ini dikarenakan banyaknya responden telah mematuhi untuk menggunakan APD dan dapat meminimalisir terjadinya kecelakaan kerja. 


\section{Hubungan Penerapan Ergonomi dengan Risiko kecelakaan}

Ergonomi adalah ilmu pengetahuan yang mempelajari masalah manusia dalam kaitan pekerjaannya. IImu ini berupaya untuk menyerasikan mesin dengan pekerja, tidak menganggap bahwa pekerja harus menyesuaikan diri dengan mesin dan lingkungan, pengukuran keselarasan hubungan antara pekerjaan dan pekerja memerlukan pemeriksaan sejumlah faktor.

Berdasarkan hasil uji chi square ( tabel 5 ) diperoleh $p$ value $0,006 \quad(0,05)$ Penerapan Ergonomi ada hubungan dengan risiko kecelakaan.

Dari hasil tersebut diketahui bahwa karyawan yang menerapkan ergonomi lebih sedikit dibandingkan dengan yang tidak menerapkan ergonomi pada saat bekerja .

Beberapa Karyawan yang harus berdiri lama, menjadi salah satu faktor. Hal ini disebabkan karena alat yang digunakan untuk pemotongan kayu dapat memungkinkan terjadinya Risiko Kecelakaan. Selain mengangkat kayu ke bagian produksi lain dapat menyebabkan kecelakaan pada saat bekerja.

$\mathrm{Hal}$ ini sejalan dengan penelitian Liatautin dengan judul Hubungan Penggunaan APD, Aktifitas Kerja Berulang dan Ergonomi terhadap Kecelakaan Kerja pada tenaga kerja bongkar PT. Jambi Waras tahun 2016. Menunjukkan bahwa dari $100 \%$ tidak ergonomi dalam pekerjaan bongkar terdapat 16 responden $(76,2 \%)$ pernah mengalami kecelakaan kerja dan 5 responden $(23,8 \%)$ tidak pernah megalami kecelakaan kerja. Sedangkan dari 18 responden (100\%) ergonomi dalam pekerjaan bongkar terdapat 5 responden $(27,8 \%)$ pernah mengalami kecelakaan kerja dan 13 responden (72,2\%) tidak pernah mengalami kecelakaan kerja.

\section{KESIMPULAN}

Berdasarkan hasil analisa dan pembahasan hubungan pengetahuan, Penggunaan APD, Penerapan Ergonomi dengan Risiko Kecelakaan di PT. Maruki Internasional Indonesia bagian produksi, maka dapat disimpulkan bahwa:

1. Tidak ada Hubungan antara Pengetahuan dengan Risiko Kecelakaan.

2. Tidak ada Hubungan antara Penggunaan APD dengan Risiko Kecelakaan.

3. Ada Hubungan antara Penerapan Ergonomi dengan Risiko

\section{SARAN} Kecelakaan.

Berdasarkan Kesimpulan yang telah dijelaskan, maka saran yang diajukan pada penelitian ini :

1. Diharapkan bagi karyawan agar selalu memperhatikan dan dapat menghindari faktor-faktor yang dapat menyebabkan risiko kecelakaan.

2. Diharapkan adanya pengawasan lebih ketat dari pihak perusahaan agar risiko kecelakaan dapat ditekan seminimal mungkin

\section{DAFTAR PUSTAKA}

Agiviana.Anisa.Putri. 2015. Analisis Penyerah, Presepsi,Sikap, dan Pengetahuan dan tempat Kerja terhadap perilaku Keselamatan Karyawan. SKRIPSI. Jurusan Manejemen Universitas Diponegoro.Semarang.https://www.google.com. Diakses 17 Des 2018

Andhika. Ricky. 2011. Kecelakaan akibat kerja. https:// rickyandhika .wordpress.com. Diakses 17 Des 2018.

Anies.2005. penyakit akibat kerja.11.PT Alex media kompotando.[online] diakses 2019 januari 1. Tersedia pada:https: //books .google.co. id/ books?id.

Ayu,Rezky Widya.2015. penerapan K3 dan penyakit akibat kerja pada karyawan PT.Maruki Internasional Indonesia.Makassar.jurusan kesehatan lingkungan Poltekkes Makassar. (KTI tidak diterbitkan)

BPJS. 2018 Angka Kecelakaan Kerja. Badan Penyelenggara Jaminan social.bali.https://finance.detik.com. Diakses 17 Des 2018

Bunarto. 2015 . Panduan Praktis Keselamatan \& Kesehatan Kerja untuk industry.1.1-71. Klaten:Pustakabarupress. 
Jurnal Sulolipu : Media Komunikasi Sivitas Akademika dan Masyarakat

Vol. 20 No.12020

e-issn : 2622-6960, p-issn : 0854-624X

Djatmiko, riswan dwi,2016. Keselamatan dan Kesehatan Kerja.Yogyakarta:Deepbublish.[online].diakses 2018 Des 17]; 97.tersedia pada:https://books.google.co.id/books?id.

Hamalainan. Et al. 2017. Group Public. http:// www. oit. org/ wcmsp5/ groups/ public/---asia/---robangkok/---ilo Jakarta /documents/publication/ wcms_627174.pdf. diakses 15 desember 2018.

Harrington.J.M. dan GILL.F.S. 2003. Kesehatan kerja.3.9 Kedokteran EGC.jakarta [online]. Diakses Des 17. Tersedia pada: https: //books. google.co.id/books?id.

Irzal.2016. Dasar-Dasar kesehatan dan keselamatan kerja.1.2.Kencana. Jakarta.[online] diakses 2018 Des 17.tersedia pada: https://books .google.co.id/books?id.

Listiyarini.Ratih. 2018. Dasar listrik \& Elektronik 2018,159.CV Budi Utama. Yogyakarta [online]. Diakses 2018 Des 17.Tersedia pada:https:// books.google.co.id/books?id.

Manguneh.alfian et al. 2007. Alat pelindung diri. https:// www. scribd.com/ doc/31588533/AlatPelindung-Diri K3.diakses 18 desember 2018.

Nursyamsi. 2015. Studi kondisi Ergonomic dan Psikologi tenaga kerja di PT. Maruki Internasional Indonesia.KTI. Jurusan Kesehatan Lingkungan. Politeknik kesehatan Makassar. Makassar.

Rachmawati. 2014. Hubungan antara Pengetahuan, Sikap dan Tindakan Karyawan dengan Penggunaan APD padaUnit Produksi PT. Semen Tonasa II/III,IV \& V Pangkep. Makassar: Program Diploma III Jurusan Kesehatan Lingkungan Politeknik Kesehatan Makassar. (KTI tidak diterbitkan).

Santoso, Gempur.2013.Manejemen Keselamatan \& Kesehatan Kerja. Jakarta.

Nulianti. Feri. 2010. IT ergonomic. Jakarta:[online][diakses pada 2018 Des 18]. Tersedia pada: https://books.google.co.id/books?id.

Republik. 2016 Peraturan Menteri Kesehatan Republik Indonesia Nomor 70 Tahun 2016

Tentang Standar Dan Persyaratan Kesehatan Lingkungan Kerja Industri.

Republik. 2010 Peraturan Menteri Tenaga Kerja Dan Treansmigrasi Republik Indonesia Nomor 7 tahun 2010 Tentang Alat Pelindung Diri.

Suwardi. Dan Daryanto. 2018.Pedoman Praktis K3LH. Keselamatan dan Kesehatan Kerja dalam Lingkungan Hidup.cetakan 1. Yogyakarta : Gava Media..

Ria.A. 2016 Keselamatan dan Kesehatan Kerja.[online].[diakses 2018 Des 11).7.tersedia pada: http:// eprints. polsri. ac. id/3085/3/ BAB \%20ll.pdf 